$p$-ISSN 1693-9484, $e$-ISSN : 2621-8313

Majalah Ilmiah Bahari Jogja (MIBJ)

Vol. 16 No. 2, Juli 2018 (148-167)

(C) 2018 Akademi Maritim Yogyakarta

\title{
ANALISIS SIMULATOR KAPAL STSTC SEBAGAI SARANA PEMBELAJARAN UTAMA DI AMY
}

\author{
Yudhi Setiyantara $^{1^{*}}$, Bambang Soedijono ${ }^{2}$, Eko Pramono $^{3}$ \\ ${ }^{1}$ Akademi Maritim Yogyakarta, Jl. Magelang KM 4.4, Sinduadi, Mlati, Sleman, \\ Yogyakarta 55284, Indonesia \\ ${ }^{2,3}$ Universitas Amikom Yogyakarta, Jl.Ring Road Utara, Condongcatur, Depok, Sleman, \\ Yogyakarta, Indonesia. \\ * Corresponding Author. E-mail: yudyoudhi@gmail.com. Telp:+628562562117
}

\begin{abstract}
Abstrak
Pada tanggal 08 Oktober 2016, diresmikan sebuah laboratorium simulator STSTC (Scientific and Technical Simulator Training Centre) yang dimiliki Akademi Maritim Yogyakarta. Permasalahan akan tingkat penerimaan dan kepuasan taruna Nautika terhadap laboratorium simulator sebagai sarana pembelajaran utama ini dapat dipelajari dengan studi berdasarkan Technology Acceptance Model (TAM). Penelitian dilakukan untuk mendapatkan inti permasalahan dan penyebab minimnya penerimaan dan kepuasan taruna Nautika terhadap laboratorium simulator yang ada. Item untuk mengukur faktor kemanfaatan (usefulness) dan Kemudahan Penggunaan (ease of use) diambil dari Davis F.D (1989). Sedangkan item untuk mengukur kepuasan pengguna sistem diambil dari Doll dan Torkzadeh (1988). Semua variabel tersebut diukur dengan berdasarkan skala Likert.Hasil penelitian menunjukkan bahwa secara umum penerimaan Taruna Nautika terhadap laboratorium simulator STSTC terutama fitur bridge simulator sudah cukup baik, hanya saja belum bisa dikatakan sangat baik karena mendapatkan nilai yang relatif rendah pada bagian kepuasan penggunaan.
\end{abstract}

Kata Kunci: technology acceptance model, tingkat kepuasan, laboratorium simulator

\begin{abstract}
On October 8th, 2016, it was inaugurated a simulator laboratory of STSTC (Scientific and Technical Simulator Training Center) owned by AMY (Yogyakarta Maritime Academy). The problem of the acceptance and satisfaction level of Nautical cadets to the simulator laboratory as the main learning media can be observed by a study based on Technology Acceptance Model (TAM). Research conducted to get the core problems that caused lack of motivation and satisfaction of Nautical cadets to the existing simulator laboratory. Items for measuring usefulness and ease of use are taken from Davis F.D (1989). Items for measuring user satisfaction are taken from Doll and Torkzadeh (1988). All these variables are measured by Likert scale. The results show that generally the acceptance of Nauticalcadets to the STSTC laboratory simulator especially the simulator bridge is good enough, but could not reach the maximum score caused by relatively low score on the satisfaction value.
\end{abstract}

Keyword: technology acceptance model, satisfaction level, simulator laboratory 


\section{PENDAHULUAN}

Pada tanggal 08 Oktober 2016, diresmikan sebuah laboratorium simulator (Bridge Simulator, GMDSS, Radar Arpa) adalah produk dari STSTC (Scientific and Technical Simulator Training Centre) yang dimiliki AMYdan diresmikan oleh Sri Sultan Hamengkubuwono X, dan disaksikan oleh Bupati Sleman, dan perwakilan dari Dinas Perhubungan, Direktorat Jenderal Perkapalan dan Kelautan, serta perwakilan beberapa kampus maritim lainnya. Laboratorium simulator ini sendiri pengadaan dan penggunaannya diatur dan dianjurkan sebagai sarana pembelajaran utama sesuai regulasi internasional STCW (Standards of Training, Certification and Watchkeeping for Seafarers) 1978 amandemen Manila tahun 2010, IMO Model Course 7.03 dan 7.04, Kurikulum Diklat Maritim (PPSDM Dirjen Perla 2016) termasuk peraturan Menteri Perhubungan PM 140 tahun 2016. Namun, pengakuan laboratorium simulator (Bridge Simulator, GMDSS, Radar Arpa) yang dimiliki oleh AMY ini dalam proses persetujuan oleh pemerintah, belum berarti bahwa laboratorium simulator (Bridge Simulator, GMDSS, Radar Arpa) ini telah disadari penuh oleh para taruna Nautika sebagai sarana pembelajaran utamanya. Hal ini didukung oleh data keikutsertaan taruna Nautika dalam pelatihan berkala dan sertifikasi pengoperasian laboratorium simulator, yang rasionya masih sedikit jika dibandingkan dengan jumlah populasi taruna Nautika yang ada.

Permasalahan akan tingkat penerimaan dan kepuasan taruna Nautika terhadap laboratorium simulator sebagai sarana pembelajaran utama ini dapat diukur dengan studi berdasarkan Technology Acceptance Model (TAM) dengan menggunakan perhitungan skala Likert. Skala Likert untuk mengukur perilaku kerjasama individu yaitu dengan mengukur variabel ideologi, perspektif, pelatihan pribadi, dan pelatihan orang lain.

Berdasarkan latar belakang di atas, maka dilakukanlah penelitian dengan judul "ANALISIS SIMULATOR KAPAL STSTC SEBAGAI SARANA PEMBELAJARAN UTAMA DI AMY" agar pihak Akademi Maritim Yogyakarta dapat lebih baik memetakan penyebab dan permasalahan minimnya 
pemahaman taruna Nautika terhadap laboratorium simulator (Bridge Simulator, GMDSS, Radar Arpa) sebagai sarana pembelajaran yang utama.

\section{KAJIAN LITERATUR}

Peneliti bernama Chen Chen, Shigeaki Shiotani, dan Kenji Sasa membahas bagaimana metode simulasi numerical navigation dapat menghasilkan estimasi lokasi kapal secara efektif ketika dikenai ombak besar dan hujan badai. Penelitian ini mempelajari seberapa terpengaruh navigasi kapal terhadap faktor-faktor alam yang seringkali mengganggu perjalanan kapal. Peneliti mengkaji besaran dampak dari beberapa proses simulasi seperti simulasi angin, kalkulasi arus air, simulasi ombak, dan simulasi manuver kapal. Jurnal memuat kelengkapan seperti teori, paparan data dalam bentuk tabel dan gambar, serta proses perhitungan dari simulasi-simulasi yang ada.

M. Arenius, G. Athanassion, dan O.Strater memaparkan penelitian tentang penilaian pengaruh kelelahan mental dan ketegangan pada performa marinir ketika mengoperasikan simulator kendali kapal. Terdapat dua studi yang diuraikan oleh peneliti sebagai bagian dari pendekatan sistemik untuk penilaian performa ketika mengoperasikan simulator nautika. Studi pertama menerapkan metode penelitian eksperimen semu yang bertujuan untuk memilah penyebab sistemik di balik human error yang dilakukan oleh siswa nautika. Studi kedua bertujuan untuk mengeksplorasi dampak dari perubahan terkait situasi seperti amarah dan frustasi. Laporan penelitian menggambarkan kejelasan dan simpulan yang didapatkan melalui dua studi pendekatan perihal kaitan antara kelelahan mental dan ketegangan pada performa siswa nautika.

Penelitian oleh Boris Gauss dan Matthias Rotting, membahas tentang pendukung kesadaran akan risiko situasional ketika menavigasikan kapal. Peneliti memaparkan bagaimana pentingnya situational risk awareness (SRA) pengendali navigasi dalam hal pengambilan keputusan antara sistem mesin dan manusia. Jurnal ini menyajikan studi evaluasi dari Navigational Risk Detection and Assessment System (NARIDAS), yang dilakukan pada simulator kendali kapal dan menunjukkan adanya dampak positif NARIDAS pada SRA dan performa navigasi. 
Penelitian dilakukan pada simulator Elsfleth yang terdapat di Lower Saxony, Jerman.

Bondan Hendar Adiwibowo, Muhammad Agung Santoso, Firman Ady Nugroho dan Yulianto S. Nugroho pada jurnal penelitiannya mengatakan bahwa kebakaran merupakan fenomena kompleks tidak terkendali yang merupakan interaksi antara aliran fluida udara sekitar, transfer panas dan massa, struktur bangunan, dan reaksi kimia bahan mampu bakar. Karena sifatnya yang tidak terkendali, kebakaran dapat menimbulkan kerugian jiwa dan properti yang sangat memprihatinkan. Salah satu kejadian kebakaran yang mengkhawatirkan adalah kebakaran yang terjadi di kapal. Tindakan penanggulangan dapat direncanakan, salah satunya, dengan berlandaskan kejadian kebakaran yang telah terjadi. Simulasi numerik fenomena kebakaransebagai alat studi dan rekayasa teknik merupakan salah satu perangkatyang dapat membantu kegiatan investigasi untuk rekonstruksi kebakaran. Pada studi ini, simulasi numerik dilakukan dengan menggunakan paket piranti lunak Fire Dynamic Simulator versi 5.0 (FDS V5) yang dibuat dan dikompilasi oleh National Institute of Science and Technology (NIST) Amerika Serikat. Rekonstruksi kebakaran dengan menggunakan perangkat numerik yang dilakukan pada studi ini adalah rekonstruksi kebakaran yang terjadi di kamar mesin KM Salvia.

Penelitian oleh Eko Sasmito Hadi, Berlian Arswendo A, dan Firdaus S.P, berisi tentang hasil perbandingan antara rancangan simulasi pada mesin induk kapal (main engine) menggunakan software instrument dan data pada test record dengan kontrol monitoring basis web melalui jaringan wireless dan powerline communication. Penulis mendapatkan selisih perbedaan sekitar 1\% - 2\% antara simulasi pada mesin induk kapal (main engine) menggunakan software instrument dengan data test record.

Amal Qurany pada penelitiannya mengungkapkan bahwa latihan mengemudi pesawat untuk seorang calon pilot dilakukan di dalam dalam ruangsimulasi pesawat terbang yang didesain sedemikian rupa sehingga memberikan kesan yang realistis bagi calon penggunanya. Kerangka ruangan simulator pesawat tersebut merupakan aplikasi dari quaternion yang dijelaskan pada penelitian. Quaternion merupakan 
notasi yang lebih sederhana untuk merepresentasikan dan melakukan operasi padabilangan kompleks. Quaternion banyak digunakan untuk merotasikan sebuah vektor. Dari penjabaran di atas kita mengetahui bahwa konsep quaternion dapat digunakan untuk mendesain kerangka simulator pesawat terbang agar simulator pesawat terbang terasa lebih realistis saatdigunakan. Kerangka yang dimaksud memiliki tiga buah sumbu yang merepresentasikan masing-masing kontrol pesawat terbang. Untuk memperjelas permasalahan yang akan diangkat dan dibahas untuk menghasilkan solusi, maka dirumuskan beberapa masalah sebagai berikut :

1. Bagaimana tingkat penerimaan dan kepuasan taruna Nautika terhadap laboratorium simulator (Bridge Simulator, GMDSS, Radar Arpa) yang ada?

2. Bagaimana uraian permasalahan dan penyebab minimnya penerimaan dan kepuasan taruna Nautika terhadap laboratorium simulator (Bridge Simulator, GMDSS, Radar Arpa) yang ada?

3. Bagaimana rekomendasi yang bisa diberikan kepada pihak Akademi Maritim Yogyakarta untuk meningkatkan penerimaan dan kepuasan taruna Nautika terhadap laboratorium simulator (Bridge Simulator, GMDSS, Radar Arpa) yang ada sebagai sarana pembelajaran yang utama?

\section{METODE PENELITIAN}

Penelitian yang dilakukan merupakan penelitian deskriptif. Penelitian deskriptif adalah suatu penelitian yang digunakan untuk menggambarkan atau menganalisis suatu hasil penelitian tetapi tidak digunakan untuk membuat kesimpulan yang lebih luas. (Sugiyono, 2005). Tujuan dari penelitian deskriptif ini adalah untuk membuat deskripsi, gambaran, atau lukisan secara sistematis, faktual dan akurat mengenai fakta-fakta, sifat-sifat serta hubungan antar fenomena yang diselidiki sehingga memperoleh informasi mengenai keadaan saat ini dan melihat kaitan antar variabel. (Dian Eka Budi Yanti, Subiki, Yushardi, 2016).

Desain penelitian yang digunakan menggunakan teori Technology Acceptance Model (TAM). TAM merupakan teori yang digunakan untuk menjelaskan penerimaan individual terhadap penggunaan sistem teknologi (Jogiyanto, 2008). Penelitian ini menerapkan penggunaan teori TAM untuk 
menjelaskan tingkat penerimaan dan kepuasan taruna nautika terhadap laboratorium simulator pada Akademi Maritim Yogyakarta.

Populasi adalah wilayah generalisasi yang terdiri atas obyek/subyek yang mempunyai kuantitas dan karakteristik tertentu yang ditetapkan oleh peneliti untuk dipelajari dan kemudian ditarik kesimpulannya (Sugiyono, 2007). Sampel adalah bagian terkecil dari anggota populasi yang diambi menurut prosedur tertentu sehingga dapat mewakili populasinya secara representatif (Satori dan Komariah, 2010). Penentuan jumlah sampel tergantung pada besarnya jumlah populasi. Jika populasi kurang dari 100, dianjurkan semuanya dijadikan sampel. Namun jika populasi lebih dari 100, maka dapat diambil 10-15\%, 20-25\%, atau lebih tergantung dari kemampuan peneliti (Arikunto, 2006). Dalam penelitian ini yang menjadi sampel subyek adalah taruna Nautika dari semester 4 hingga semester 6 dengan jumlah 120 orang.

Teknik pengumpulan data pada penelitian ini menggunakan angket, yaitu dengan cara menyebarkan sejumlah pertanyaan tertulis kepada responden, yang dalam hal ini merupakan taruna Nautika dengan jumlah 120 orang. Dengan tujuan untuk mendapatkan data tentang penerimaan dan kepuasan taruna Nautika kepada laboratorium simulator yang dimiliki oleh Akademi Maritim Yogyakarta sebagai sarana pembelajaran yang utama.

Angket yang digunakan merupakan tes skala sikap yang memiliki beberapa alternatif skala perhitungan, yaitu:

1. Skala Guttman, untuk mengukur secara tegas dan konsisten tentang sikap, pendapat, persepsi seseorang atau sekelompok orang tentang fenomena tertentu yang ingin diketahui. Namun dalam skala Guttman hanya disediakan dua alternatif jawaban (dikotomi), misalnya: Ya - tidak; setuju - tidak setuju; pernah - tidak pernah. Sehingga jika datanya dikuantitatifkan, nilainya hanya 0 atau 1 saja, atau hanya 1 atau 2 saja. Data yang diperoleh dari angket skala Guttman dapat dikategorikan skala nominal atau ordinal.

2. Skala Thurstone, untuk mengukur tentang sikap, persepsi seseorang atau sekelompok orang tentang fenomena tertentu yang ingin diketahui. Hasil dari angket skala Thurstone adalah sejumlah pernyataan yang biasanya sekitar 20 
buah dimana posisi pernyataan-pernyataan telah diketahui berdasarkan penilaian para ahli. Kepada responden diminta untuk memilih sebuah pernyataan yang paling disetujuinya atau disuruh mengecek memilih 2 atau 3 pernyataan yang paling disukai responden. Data yang diperoleh dari angket skala Thurstone termasuk skala interval (Nazir, 2003).

3. Skala Likert, untuk mengukur sikap, pendapat, persepsi seseorang atau sekelompok orang tentang fenomena tertentu yang ingin diketahui (Sugiyono, 2007). Dalam angket skala Likert biasanya disediakan lima alternatif jawaban, misalnya: SS, S, N, TS, dan STS (Riduwan dan Akdon, 2009). Kemudahan yang ada pada penyusunan skala Likert harus diperhatikan dengan hati-hati agar analisis lanjutan terhadap butir-butir respon tepat. Skala Likert (bukan tipe data Likert) yang mengukur sifat-sifat (traits) individu misalnya pengetahuan atau sikap dengan menggunakan skor total dari butir pertanyaan adalah skala pengukuran interval (Weksi Budiaji, 2013).

Skala Guttman tidak akan bisa menggambarkan tingkatan pemahaman dari Taruna Nautika karena hanya menyediakan dua alternatif jawaban saja, yang menghasilkan pendapat Ya atau Tidak. Penelitian ini tidak melibatkan para ahli dalam penentuan pernyataan maupun pertanyaan yang ada di dalam angket, sehingga penggunaan skala Thurstone tidak bisa digunakan. Hasil angket pada penelitian ini mengacu kepada parameter skala Likert yang mengukur pendapat dan persepsi seseorang dan mampu menghasilkan tingkatan-tingkatan berdasarkan prosentase hasil perhitungan angket. Pilihan jawaban dikategorikan sebagai suatu pernyataan sikap SS (sangat setuju / sangat baik), S (setuju / baik), TS (tidak setuju / tidak baik), dan STS (sangat tidak setuju / sangat tidak baik). Kategori ragu-ragu (R) tidak diikutsertakan untuk menghindari sikap keragu-raguan pada responden.

Data yang diperoleh dari hasil angket kemudian diolah dengan garis besar tahapan sebagai berikut:

1. Mengklasifikasi dan menentukan skor atas alternatif jawaban responden yang cocok tergantung pada anggapan atau opini responden. Penghitungan skor 
dilakukan menggunakan skala Likert yang pengukurannya adalah sebagai berikut :
a. Skor 4 untuk jawaban Sangat Setuju / Sangat Baik
b. Skor 3 untuk jawaban Setuju / Baik
c. Skor 2 untuk jawaban Tidak Setuju / Tidak Baik
d. Skor 1 untuk jawaban Sangat Tidak Setuju / Sangat Tidak Baik

2. Membuat tabel-tabel yang berisikan data yang telah diberi skor sesuai dengan analisis yang dibutuhkan.

3. Menentukan besar prosentase alternatif jawaban responden.

4. Mencocokan hasil hitung prosentase dengan predikat intensitas penerimaan Taruna Nautika tentang laboratorium simulator terutama pada bagian simulator navigasi (bridge simulator).

Metode Analisis Data Data hasil angket selanjutnya akan dianalisis dan diberi makna atas data yang disajikan tersebut. Setiap hasil angket yang diperoleh dari sampel akan menghasilkan prosentase sebagai berikut:

$$
\mathrm{T}=n / N \times 100 \%
$$

Dengan :

$\mathrm{T}=$ prosentase tiap angket

$\mathrm{n}=$ skor angket yang diperoleh

$\mathrm{N}=$ skor angket seluruhnya

Prosentase angket mewakili interpretasi skor yang ditunjukkan pada Tabel 2 sebagai berikut :

Tabel.2. Analisis prosentase tiap angket

\begin{tabular}{|c|c|}
\hline Prosentase Tiap Angket & Interpretasi Skor \\
\hline Angka $0 \%-24,99 \%$ & Sangat (tidak setuju/buruk/kurang) \\
\hline Angka $25 \%-49,99 \%$ & Tidak setuju / Kurang baik \\
\hline Angka $50 \%-74,99 \%$ & Setuju / Baik \\
\hline Angka $75 \%-100 \%$ & Sangat (setuju/Baik/Suka) \\
\hline
\end{tabular}

Majalah Ilmiah Bahari Jogja | 155 | http://jurnal.amy.ac.id/index.php/MIBJ/ 
Kumpulan prosentase angket kemudian akan dihitung rata-ratanya dengan rumus sebagai berikut:

$$
\mathrm{P}=(\mathrm{T} 1+\mathrm{T} 2+\mathrm{T} 3+\ldots+\mathrm{Tn}) / \mathrm{n}
$$

Dengan:

$\mathrm{P} \quad=$ prosentase akhir semua angket

$\mathrm{Tn}=$ prosentase tiap angket

$\mathrm{n} \quad$ jumlah angket

Prosentase akhir dapat ditafsirkan dalam bentuk kalimat (kualitatif) yang ada pada Tabel 3. guna mengetahui sejauh mana tingkat pemahaman taruna Nautika terhadap laboratorium simulator kapal sebagai sarana pembelajaran yang utama, maka digunakan analisis prosentase.

Tabel 3. Analisis prosentase akhir angket

\begin{tabular}{|l|l|}
\hline $\begin{array}{l}\text { Prosentase Intensitas Penerimaan } \\
\text { Taruna }\end{array}$ & $\begin{array}{l}\text { Predikat dari Intensitas Penerimaan } \\
\text { Taruna }\end{array}$ \\
\hline $75 \%<=\mathrm{T}>100 \%$ & Sangat Baik \\
\hline $50 \%<=\mathrm{T}>75 \%$ & Baik \\
\hline $25 \%<=\mathrm{T}>50 \%$ & Kurang Baik \\
\hline $0 \%<\mathrm{T}>25 \%$ & Tidak Baik \\
\hline
\end{tabular}

Laboratorium simulator (Bridge Simulator, GMDSS, Radar Arpa) produk STSTC dikatakan memenuhi standar dan menjadi sarana pembelajaran utama apabila sesuai dengan STCW 1978 amandemen Manila tahun 2010, IMO Model Course 7.03 dan 7.04, Kurikulum Diklat Maritim (PPSDM Dirjen Perla 2016) termasuk peraturan Menteri Perhubungan PM 140 tahun 2016.

Setelah mendapatkan predikat intensitas penerimaan Taruna Nautika akan laboratorium simulator kapal sebagai sarana pembelajaran utamanya, data hasil angket juga dapat digunakan untuk memetakan permasalahan yang menjadi penyebab kurangnya pemahaman dan kepuasan responden bahwa laboratorium simulator merupakan sarana pembelajaran yang utama. Hal ini dilakukan dengan menyeleksi angket yang mendapatkan jawaban dengan skor 1 atau 2 
(menggambarkan sangat tidak setuju / sangat tidak baik dan tidak setuju / tidak baik).

Alur Penelitian memiliki alur yang ditunjukkan oleh diagram pada Gambar 1 sebagai berikut:

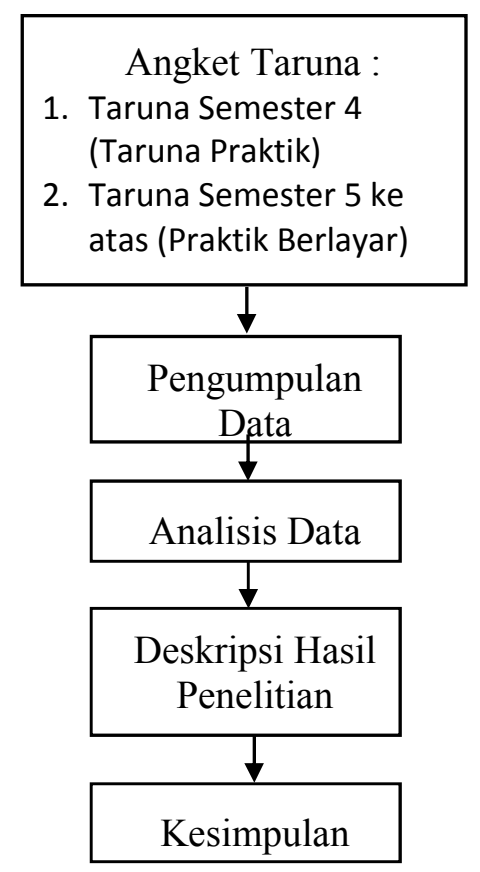

Gambar 1. Diagram Alur Penelitian

\section{PEMBAHASAN}

Laboratorium Simulator. Sejarah singkat simulator telah datang relatif lama dan sekarang secara luas diakui dan diterima oleh dunia pendidikan menjadi alat pelatihan yang efektif. Dalam skenario baru, kita membayangkan simulator menawarkan peluang yang menjanjikan sesuai harapan dan juga cara alternatif yang kuat dari pengajaran dan pembelajaran, melalui presentasi yang lebih baik, keterlibatan indra dan pengalaman belajar. Simulator pada siswa dan sebagian besar daya tarik melalui pendekatan multi-sensor, pendekatan dari text, efek visual dan audio dalam tahap awal, kehadiran pelatih yang menghubungkan antara dunia nyata dan representasi maya dari dunia itu. Pengalaman simulasi memberikan gaya belajar yang lebih bermakna dan lebih tinggi. Terlepas dari pendekatan pengalaman di mana siswa memainkan peran sentral dalam proses belajar, pelatih memberikan 
kesempatan untuk belajar melalui pendekatan pemeriksaan, memunculkan pertanyaan dan mendiskusikan konsep-konsep yang kompleks (Training Course for Train the Simulator Trainer and Assessor, IMO Model Course 6.10).

Simulator Kapal STSTC (Scientific and Technical Simulator Training Centre). Simulator radar dan navigasi kapal dari STSTC didesain untuk memenuhi kebutuhan pelatihan mulai dari pelatihan personal hingga kebutuhan pelatihan menyeluruh, termasuk di dalamnya adalah ARPA / radar, ECDIS, peralatan GMDSS, ruang kendali kapal, visualisasi tiga dimensi, AIS, dan bantuan navigasi. Simulator navigasi STSTC (Full Mission Bridge) adalah simulator dengan sebuah bridge kapal yang mana para kru seperti kapten, pilot, juru pengemudi dapat melaksanakan semua macam kegiatan yang biasanya dilakukan di lapangan. Kegiatan yang dimaksud adalah masuk dan keluarnya kapal dari pelabuhan, navigasi pada saat kanal sedang sibuk / penuh, dan lainnya. Singkatnya, FMB simulator, DNV simulator kelas A, seringkali digunakan untuk pelatihan dan / atau melakukan penilaian terhadap juru mudi dalam hal mengemudikan kapal di berbagai situasi, termasuk keadaan darurat. Hal ini menjadikan simulator navigasi sangat diperlukan keberadaan dan pemanfaatannya untuk menunjang keberhasilan pelatihan dan pendidikan baik untuk marinir pemula ataupun yang sudah berpengalaman. Simulator navigasi STSTC dirancang berdasarkan resolusi IMO dan menyediakan pelatihan sesuai dengan ketentuan yang ada pada standar STCW pada bidang:

- Observasi dan perencanaan radar

- Bantuan untuk perencanaan radar otomatis

- Pemetaan elektronik

- Manuver dan kendali kapal

Technology Acceptance Model (TAM). Model Penerimaan Teknologi merupakan salah satu teori tentang penggunaan sistem teknologi informasi yang dianggap sangat berpengaruh dan umumnya digunakan untuk menjelaskan penerimaan individual terhadap penggunaan sistem teknologi informasi (Jogiyanto, 2008). TAM pertama dikembangkan oleh Davis (1985) berdasarkan model Theory

Majalah Ilmiah Bahari Jogja 158 | http://jurnal.amy.ac.id/index.php/MIBJ/ 
of Reasoned Action (TRA). Kelebihan TAM yang paling penting adalah TAM merupakan model parsimoni, yaitu model yang sederhana tetapi valid. Selain itu, TAM juga telah diuji dengan banyak penelitian yang hasilnya TAM merupakan model yang baik khususnya jika dibandingkan dengan model TRA dan TPB.

Dalam TAM, penerimaan pengguna dalam penggunaan teknologi dipengaruhi oleh dua konstruk, yaitu kegunaan (perceived usefulness) dan kemudahan penggunaan (perceived ease of use). Kedua konstruk tersebut merupakan perbedaan paling mencolok yang ada pada TAM jika dibandingkan dengan TRA dan TPB. Selain itu, dalam TAM juga tidak terdapat konstruk norma subjektif (subjective norm) dan kontrol perilaku (perceived behavioral control). Konstruk lain dalam TAM sama dengan TRA, hanya karena lebih dikhususkan untuk penggunaan teknologi, maka istilahnya pun menyesuaikan. Model TAM ditunjukkan pada Gambar 2 seperti berikut :

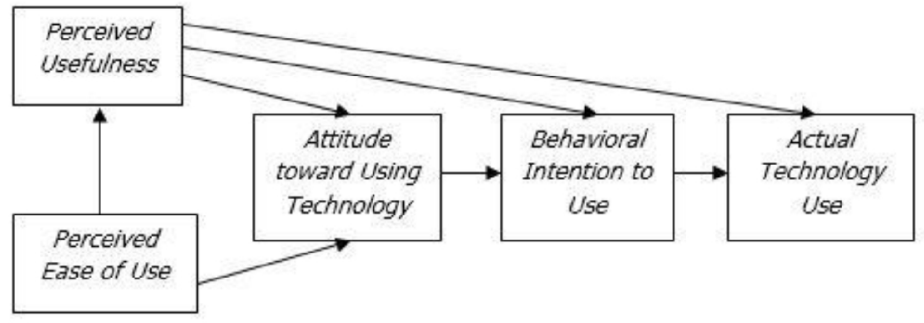

Gambar 2. Technology Acceptance Model (Jogiyanto, 2008)

TAM memiliki 5 konstruk utama, yaitu: (1) Perceived usefulness (kegunaan), (2) Perceived ease of use (kemudahan penggunaan), (3) Attitude toward using technology (sikap), (4) Behavioral intention to use (intensi), dan (5) Actual technology use (penggunaan teknologi sesungguhnya). Penjelasan masing-masing konstruk adalah sebagai berikut.

Konstruk pertama adalah perceived usefulness yang selanjutnya disebut kegunaan. Kegunaan didefinisikan sebagai sejauh mana seseorang percaya bahwa menggunakan suatu teknologi akan meningkatkan kinerja pekerjaannya (Davis, 1985). Konstruk ini dipengaruhi oleh konstruk kemudahan penggunaan. Penelitian terdahulu menunjukkan bahwa kegunaan merupakan konstruk yang paling banyak signifikan dan penting yang mempengaruhi sikap, intensi dan perilaku (Jogiyanto, 2008). Terdapat 6 indikator untuk mengukur konstruk kegunaan yaitu pekerjaan 
lebih cepat selesai (work more quickly), meningkatkan kinerja (job performance), meningkatkan produktivitas (increase productivity), meningkatkan efektivitas kerja (effectiveness), memudahkan pekerjaan (makes job easier) dan berguna (useful) (Davis, 1989 dalam Jogiyanto).

Konstruk kedua adalah perceived ease of use yang selanjutnya disebut kemudahan penggunaan. Kemudahan penggunaan didefinisikan sebagai sejauhmana orang percaya bahwa menggunakan suatu teknologi akan bebas dari usaha (Davis, 1985). Konstruk ini memengaruhi konstruk kegunaan, sikap, intensi dan penggunaan teknologi sesungguhnya. Namun yang paling signifikan adalah pengaruh ke konstruk kegunaan, sementara terhadap konstruk lain pengaruhnya tidak signifikan (Jogiyanto, 2008). Terdapat 6 indikator untuk mengukur konstruk kemudahan penggunaan yaitu kemudahan sistem untuk dipelajari (easy of learn), kemudahan system untuk dikontrol (controllable), interaksi dengan system yang jelas dan mudah dimengerti (clear and understandable), fleksibilitas interaksi (flexibility), mudah untuk terampil menggunakan sistem (easy to become skillful) dan mudah untuk digunakan (easy to use) (Davis, 1989 dalam Jogiyanto, 2008).

Konstruk ketiga adalah attitude towardusing technology yang selanjutnya disebut sikap. Sikap dapat didefinisikan sebagai perasaan positif atau negatif dari seseorang jika harus melakukan perilaku yang akan ditentukan (Davis dkk, 1989 dalam Jogiyanto, 2008). Dalam model TAM, sikap berpengaruh pada intensi serta dipengaruhi oleh kemudahan penggunaan dan kegunaan. Jogiyanto (2008) juga menyatakan bahwa dalam penelitian-penelitian yang sudah pernah dilakukan, sebagian menunjukkan bahwa sikap memiliki pengaruh positif pada intensi, namun sebagian yang lain juga menunjukkan bahwa sikap tidak memiliki pengaruh yang signifikan ke intensi. Oleh sebab itu, ada penelitian TAM tidak menyertakan konstruk sikap dalam modelnya.

Konstruk keempat adalah behavioral intention to use yang selanjutnya disebut intensi. Terdapat 2 indikator untuk mengukur konstruk intensi, yaitu penggunaan sistem untuk menyelesaikan pekerjaan (carrying out the task) dan rencana 
pemanfaatan di masa depan (planned utilization in the future) (Amoroso dan Gardner, 2004).

Konstruk kelima adalah actual technology use yang selanjutnya disebut penggunaan teknologi sesungguhnya atau penggunaan. Dalam TAM, penggunaan teknologi sesungguhnya setara dengan istilah perilaku (behavior) pada TRA namun untuk digunakan dalam konteks teknologi. Konstruk ini dipengaruhi langsung oleh intensi dan kegunaan. Terdapat 3 indikator pengukuran konstruk penggunaan teknologi yaitu penggunaan sesungguhnya, frekuensi sesungguhnya dan kepuasan pengguna (Wibowo, 2006).

Gambaran Umum Obyek Penelitian Akademi Maritim Yogyakarta (AMY) sebagai institusi pendidikan dan pelatihan (Diklat) Kepelautan berdiri pada tahun 1964 yang bertujuan menghasilkan lulusan memiliki kompetensi bidang kepelautan dan berorientasi untuk memenuhi kebutuhan industri pelayaran baik nasional maupun internasional. AMY memiliki komitmen tinggi untuk melaksanakan regulasi nasional dan International sesuai STCW 1978 dan amandemennya.

Dalam perkembangannya AMY untuk dapat eksis dan mampu bersaing dengan perguruan tinggi lain dalam mengisi dunia kerja memerlukan arah dan strategi-strategi, sehingga peningkatan kualitas lulusan berjalan secara terusmenerus seiring dengan perkembangan tatanan dan regulasi bidang kepelautan yang berlaku. Dukungan pemerintah terhadap dunia pelayaran saat ini sangat kuat dengan dicetuskannya adanya tol laut di wilayah Indonesia, hal ini membuka peluang yang seluas-luasnya bagi semua elemen khususnya yang terkait dengan industri maritim. Peluang sekaligus tantangan ini bagi Akademi Maritim Yogyakarta yang merupakan salah satu institusi yang mengahsilkan SDM pelayaran harus mampu memberikan kontribusi yang positif, sehingga dapat berperan serta secara aktif untuk peningkatan perkembangan pelayaran tersebut.

Deskripsi Data Kuesioner diberikan kepada taruna Nautika semester 4 ke atas, yang sudah pernah menggunakan laboratorium simulator. Kuesioner berisi 25 item pertanyaan. Dua puluh item pertanyaan terbagi menjadi 10 pertanyaan untuk menilai konstruk kegunaan (TAM), 10 pertanyaan untuk menilai konstruk kemudahan penggunaan (TAM), dan 5 pertanyaan lagi untuk menilai tingkat 
kepuasan. Pertanyaan-pertanyaan untuk setiap variabel berasal dari item-item yang sudah divalidasi dari penelitian-penelitian yang sudah dilakukan sebelumnya. Item untuk mengukur faktor kemanfaatan (usefulness) dan Kemudahan Penggunaan (ease of use) diambil dari Davis F.D (1989). Sedangkan item untuk mengukur kepuasan pengguna sistem diambil dari Doll dan Torkzadeh (1988). Semua variabel tersebut diukur dengan berdasarkan skala Likert.

Kuesioner disebarkan kepada 120 responden yang merupakan mahasiswa Taruna Nautika yang dari semester 4 ke atas. Penyebaran kuesioner dilakukan secara langsung kepada responden. Penyebaran kuesioner dimulai pada tanggal 1 April 2017 sampai dengan 14 April 2017.

Pengolahan Data Hasil dari kuesioner yang diberikan kepada Taruna Nautika kemudian diolah dengan cara mengklasifikasikan dan memberikan skor atas alternatif jawaban responden dengan menggunakan skala Likert yang menghasilkan rekapitulasi yang ditunjukkan pada Tabel 4, 5, dan 6 sebagai berikut:

Tabel 4. Hasil Kuesioner Konstruk Kegunaan (TAM)

\begin{tabular}{|l|l|l|l|l|l|l|l|}
\hline No & STS & ST & S & SS & $\begin{array}{l}\text { Total } \\
\text { Skor }\end{array}$ & $\begin{array}{l}\text { Rata- } \\
\text { Rata }\end{array}$ & Persentase \\
\hline 1 & 8 & 13 & 39 & 60 & 391 & 3,26 & 81,46 \\
\hline 2 & 9 & 12 & 33 & 66 & 396 & 3,30 & 82,50 \\
\hline 3 & 13 & 14 & 41 & 52 & 372 & 3,10 & 77,50 \\
\hline 4 & 10 & 11 & 41 & 58 & 387 & 3,23 & 80,63 \\
\hline 5 & 12 & 14 & 42 & 52 & 374 & 3,12 & 77,92 \\
\hline 6 & 10 & 23 & 49 & 38 & 355 & 2,96 & 73,96 \\
\hline 7 & 8 & 12 & 40 & 60 & 392 & 3,27 & 81,67 \\
\hline 8 & 7 & 10 & 32 & 71 & 407 & 3,39 & 84,79 \\
\hline 9 & 18 & 13 & 36 & 53 & 364 & 3,03 & 75,83 \\
\hline 10 & 22 & 12 & 37 & 49 & 353 & 2,94 & 73,54 \\
\hline Rata- & & & & & & $\mathbf{3 , 1 6}$ & $\mathbf{7 8 , 9 8}$ \\
\hline rata & & & & & & & \\
\hline
\end{tabular}


Tabel 5. Hasil Kuesioner Konstruk Kemudahan Penggunaan (TAM)

\begin{tabular}{|l|l|l|l|l|l|l|l|}
\hline No & STS & ST & S & SS & $\begin{array}{l}\text { Total } \\
\text { Skor }\end{array}$ & $\begin{array}{l}\text { Rata- } \\
\text { Rata }\end{array}$ & Persentase \\
\hline 1 & 13 & 12 & 46 & 49 & 371 & 3,09 & 77,29 \\
\hline 2 & 13 & 14 & 44 & 49 & 369 & 3,08 & 76,88 \\
\hline 3 & 21 & 32 & 25 & 42 & 328 & 2,73 & 68,33 \\
\hline 4 & 12 & 9 & 33 & 66 & 393 & 3,28 & 81,88 \\
\hline 5 & 27 & 28 & 23 & 42 & 320 & 2,67 & 66,67 \\
\hline 6 & 16 & 19 & 39 & 46 & 355 & 2,96 & 73,96 \\
\hline 7 & 11 & 21 & 41 & 47 & 364 & 3,03 & 75,83 \\
\hline 8 & 7 & 5 & 49 & 59 & 400 & 3,33 & 83,33 \\
\hline 9 & 9 & 19 & 42 & 50 & 373 & 3,11 & 77,71 \\
\hline 10 & 12 & 34 & 33 & 41 & 343 & 2,86 & 71,46 \\
\hline Rata- & & & & & & $\mathbf{3 , 0 1}$ & $\mathbf{7 5 , 3 3}$ \\
\hline rata & & & & & & & \\
\hline
\end{tabular}

Tabel 6. Hasil Kuesioner Tingkat Kepuasan

\begin{tabular}{|l|l|l|l|l|l|l|l|}
\hline No & STS & ST & S & SS & $\begin{array}{l}\text { Total } \\
\text { Skor }\end{array}$ & $\begin{array}{l}\text { Rata- } \\
\text { Rata }\end{array}$ & Persentase \\
\hline 1 & 30 & 21 & 32 & 37 & 316 & 2,63 & 65,83 \\
\hline 2 & 42 & 36 & 22 & 20 & 260 & 2,17 & 54,17 \\
\hline 3 & 43 & 48 & 21 & 8 & 234 & 1,95 & 48,75 \\
\hline 4 & 31 & 38 & 29 & 22 & 282 & 2,35 & 58,75 \\
\hline 5 & 29 & 45 & 19 & 27 & 284 & 2,37 & 59,17 \\
\hline $\begin{array}{l}\text { Rata- } \\
\text { rata }\end{array}$ & & & & & & $\mathbf{2 , 2 9}$ & $\mathbf{5 7 , 3 3}$ \\
\hline
\end{tabular}

\section{Analisis Hasil}

Berdasarkan skala ordinal diperoleh rata-rata di atas angka 3 yaitu 3,16 untuk konstruk kegunaan. Hal ini menunjukan bahwa kegunaan (usefulness) dari 
laboratorium simulator ini telah dapat dirasakan dan diakui oleh para penggunanya yaitu Taruna Nautika, namun belum maksimal karena masih cukup jauh dari angka 4 yaitu nilai sempurna dari hasil pengolahan data. Untuk konstruk kemudahan penggunaan sendiri, mendapatkan nilai rata-rata sedikit melebihi 3, yaitu 3,01, sehingga dapat dikatakan bahwa kemudahan penggunaan dari laboratorium simulator ini juga sudah mendapatkan penerimaan yang cukup baik dari para penggunanya, namun belum cukup maksimal. Nilai yang tergolong rendah dihasilkan dari pertanyaan kuesioner yang berfokus pada tingkat kepuasan Taruna Nautika dalam menggunakan laboratorium simulator, yaitu nilai rata-rata keseluruhan 2,29. Diperlukan introspeksi dan penanganan lebih lanjut terhadap aspek kepuasan yang disebabkan dan tergambar oleh item kuesioner yang mendapatkan nilai relatif rendah, terutama pada bagian kelengkapan perangkat satuan laboratorium simulator.

Nilai prosentase akhir rata-rata menunjukkan angka $70.55 \%$, yang menunjukkan predikat "Baik". Masih diperlukan sekitar 5\% peningkatan nilai untuk mencapai batas bawah predikat "Sangat Baik" dengan nilai minimal 75\%. Hal ini tentunya menjadi masukan untuk Akademi Maritim Yogyakarta untuk segera menindaklanjuti peningkatan penerimaan Taruna Nautika akan teknologi yang dipersiapkan untuk menjadi sebuah fungsi mandatory. Sehubungan dengan hal tersebut maka perbaikan secara terus menerus perlu dilakukan. Seorang pemakai yang menganggap bahwa teknologi tersebut memberikan nilai, maka pemakai tersebut akan puas dengan sistem tersebut. Semakin tergantung seseorang pada teknologi dalam melakukan pekerjaan yang diharuskan, semakin besar pula keyakinannya pada teknologi tersebut. Semakin jelaslah bahwa pendekatan perilaku menawarkan kontribusi yang besar pada kesuksesan penerapan teknologi baru.

\section{PENUTUP}

\section{Kesimpulan}

Kesimpulan yang dapat ditarik dari pelaksanaan penelitian yang dilakukan adalah beberapa hal sebagai berikut:

Majalah Ilmiah Bahari Jogja 164 | http://jurnal.amy.ac.id/index.php/MIBJ/ 
1. Hasil penelitian menunjukkan bahwa secara umum penerimaan Taruna Nautika terhadap laboratorium simulator STSTC terutama fitur bridge simulator sudah cukup baik dengan tingkat penerimaan akhir sebesar $70.55 \%$, hanya saja belum bisa dikatakan sangat baik karena mendapatkan nilai yang relatif rendah pada bagian kepuasan penggunaan sebesar $57.33 \%$.

2. Beberapa indikasi seperti kurang lengkapnya fitur yang tersedia dari rangkaian laboratorium simulator STSTC menjadi salah satu penyebab minimnya tingkat kepuasan dari Taruna Nautika yang pernah menggunakannya. Dan indikasi lainnya dapat dilihat dari item-item kuesioner yang mendapatkan nilai cukup rendah, seperti yang terlihat pada lampiran berkas penelitian.

3. Rekomendasi yang dapat diberikan kepada Akademi Maritim Yogyakarta berdasarkan hasil penelitian adalah sebagai berikut :

a. Segera menindaklanjuti indikasi penyebab minimnya tingkat kepuasan Taruna Nautika sebelum menjadikan laboratorium simulator STSTC sebagai fungsi mandatory yang ada pada kurikulum.

b. Meningkatkan kualitas dan frekuensi pelaksanaan pelatihan agar dapat mendorong penerimaan Taruna Nautika dalam pemanfaatan laboratorium simulator STSTC sebagai sarana pembelajaran utama.

c. Menambah kelengkapan rangkaian laboratorium simulator STSTC agar dapat lebih baik menyampaikan manfaat dan kegunaannya.

\section{DAFTAR PUSTAKA}

Akdon R., 2009, Aplikasi Statistika dan Metode Penelitian untuk Administrasi dan Manajemen, Dewa Ruci, Bandung

Arikunto, S, 2006, Prosedur Penelitian Suatu Pendekatan Praktik. Jakarta

Davis, F.D, 1989, Perceived Usefulness, Perceived Ease of Use, and User Acceptance of Information Technology, Management Information System Quarterly

Doll,W.J., dan Torkzadeh, G., The Measurement of End-User Computing Satisfaction, Management Information System Quarterly

Jogiyanto, 2008, Sistem Informasi Keperilakuan. Edisi Revisi, Penerbit ANDI, Yogyakarta

Majalah Ilmiah Bahari Jogja 165 | http://jurnal.amy.ac.id/index.php/MIBJ/ 
Nazir, M. 2003, Metode Penelitian, Ghalia Indonesia, Jakarta

Salim, Peter; Yenny Salim, 2002, Kamus Bahasa Indonesia Kontemporer, Modern English Press, Jakarta

Satori, D., Komariah A., 2010, Metode Penelitian Kualitatif, Alfabeta, Bandung

Sugiyono, 2007, Metode Penelitian Kuantitatif, Kualitatif, Dan R\&D, Alfabeta, Bandung

\section{Pustaka Majalah, Jurnal Ilmiah atau Prosiding}

Adiwibowo, Bondan Hendar; Santoso, Muhammad Agung; Nugroho, Firman Ady; Nugroho, Yulianto S., 2015, Simulasi Numerik Rekonstruksi Kebakaran Di Kapal, Proceeding Seminar Nasional Tahunan Teknik Mesin XIV (SNTTM $X I V)$

Arief Wibowo, 2006, Kajian Tentang Perilaku Pengguna Sistem Informasi dengan Pendekatan Technology Acceptance Model (TAM). Diakses dari https://www.academia.edu/640386/Kajian_Tentang_Perilaku_Pengguna_Sist em_Informasi_Dengan_Pendekatan_Technology_Acceptance_Model_TAM pada 9 April 2017

Chen Chen; Shiotani, Shigeaki; Sasa, Kenji, 2013, Numerical Ship Navigation Based On Weather And Ocean Simulation, Elsevier Ocean Engineering, 2013

Davis, F.D, 1985, A Technology Acceptance Model for Empirically Testing NewEnd User Information Systems: Theory and Results. Disertasi. Massachusetts Institute of Technology

Gauss, Boris; Rötting, Matthias, 2007, Supporting Situational Risk Awareness In Ship Navigation, IFAC Proceedings Volumes Volume 40, Issue 16, 2007, Pages 342-346

Gardner, Christina dan Donald L Amoroso, 2004, Development of an Instrument to Measure the Acceptance of Internet Technology by Consumers.

Proceedings, Hawaii International Conference on System Sciences. 37. Hlm. $1-10$

Hadi; Eko Sasmito; A, Berlian Arswendo; P, Firdaus S., 2013, Designing of Simulation for Engine Room KM. Sinabung with Control Monitoring Web Server Based by Wireless Network and Power Line Communication, Ejournal UNDIP

M. Arenius; G. Athanassiou; O. Sträter, 2010 Systemic assessment of the effect of mental stress and strain on performance in a maritime ship-handling simulator, IFAC Proceedings Volumes |Vol 43, Iss 13, Pgs 1-499 
Weksi Budiaji, 2013, Skala Pengukuran Dan Jumlah Respon Skala Likert, Jurnal Ilmu Pertanian dan Perikanan Desember 2013Vol. 2 No. 2 Hal : 127-133

Qurany, Amal, 2015, Aplikasi Quaternion Dalam Desain Simulator Pesawat 